\title{
Evaluation of the Role of Intravenous Lipid Emulsion as a Putative Treatment for Acute Aluminum Phosphide Poisoning
}

\author{
Yasmeen M. Taalab ${ }^{1,}$, Manar A. Helmy ${ }^{1 *}$, Alyaa A.A. Othman ${ }^{1}$
}

\begin{abstract}
KEYWORDS

Aluminum phosphide toxicity (ALP) "Wheat pill";

Antidote;

Intralipid emulsion (ILE);

Survival time;

Mortality rate.

The study aimed to evaluate the effect of intravenous lipid emulsion (ILE) as a putative antidote on the survival time of ALP intoxicated patients and whether it ameliorates the clinical outcome or not. The present clinical study was conducted in Mansoura Emergency Hospital, and it involves patients presented with acute aluminum phosphide poisoning (ALP). Sociodemographic and full clinical examination was documented. Patients received either the standard therapy or standard therapy plus ILE. Over five years, a total of 87 acutely intoxicated patients were analyzed of which (56 were females $(64.4 \%)$, and 31 were males $(35.6 \%)$. The mean age was $28.23 \pm 9.69$ years. The mortality rate for ALP poisoning was $67.8 \%$. Despite the poor outcome of cardiopulmonary resuscitation (CPR) following ALP toxicity, the survival time among patients who received ILE was significantly longer compared to the group of patients who received only standard therapy, in which $7.3 \%$ versus $30.4 \%$ survived $6-24$ hours, $34.1 \%$ versus $21.7 \%$ survived $25-48$ hours while $36.6 \%$ versus $6.5 \%$ survived between $49-72$ hours respectively with $p$-value $=<0.001$. From previous data, it can be concluded that the use of ILE as an antidote during resuscitative measures following ALP toxicity showed a slight improvement in terms of survival time, however, it doesn't decrease the mortality rate. Further studies are imperative to prove the effectiveness of ILE as an antidote for ALP toxicity and whether it could be considered in the CPR measures of poisoning cases.
\end{abstract}

\section{Introduction}

"Wheat pill" or "rice pill" as commonly known in many agricultural countries such as in Egypt, Pakistan, India, Iran, Morocco, and Nepal, referred to as Aluminum phosphide (ALP) and zinc phosphides that are used to prevent the wheat and rice infestation (Ghazi, 2013). They have been extensively used for many years as effective insecticides and rodenticides with the major merits of being inexpensive, leaving little residue on food grains, and eliminating insects with no impact on seed viability (Proudfoot, 2009; Sankhla et al., 2017;

\footnotetext{
(1) Forensic Medicine and Clinical Toxicology Department, Faculty of Medicine, Mansoura University, 35516, Egypt.

*Corresponding author

Manar A. Helmy:

Phone: 00201004996882.

Email: manaradel1982@gmail.com.

ORCHID: 0000-0001-6075-8655 ${ }^{1}$
}

Karimani et al., 2018). Aluminum phosphide exposed to moisture produces phosphine gas, which in turn inhibits cytochrome oxidase and impair cellular oxygen consumption (Anand et al., 2011). Exposure is either accidental, occupational, or suicidal intent (Bumbrah et al., 2012, Singh and Bhalla, 2015; Alnasser et al., 2018), however, based on limitless accessibility in the developing countries, ALP has been increasingly used for suicide (Karimani et al., 2018).

Poisoning and suicide shared a medicosocial background that represents a major health concern and consumes valuable health service resources with considerable morbidity and mortality (Alnasser et al., 2018). In this context, the exact statistics for the global impact of the acute poisoning from these pills are not confidently known, however, it can be safely said that it proves fatal in most cases and despite aggressive management, only a 
few patients survive the fatal effects of the wheat pill poison (Ghazi, 2013). Mortality from ALP poisoning is elevated more than $50 \%$ and reaches up to $100 \%$ with no available antidote (Alnasser et al., 2018, Karimani et al., 2018).

Aluminum phosphide toxicity is mainly treated by supportive approaches (Hassanian - Moghaddam et al., 2016). Experimental and clinical studies suggested that magnesium sulfate, melatonin, $\mathrm{N}$ acetylcysteine, glutathione, sodium selenite, vitamin $\mathrm{C}$ and $\mathrm{E}$, triiodothyronine, liothyronine, vasopressin, milrinone, Laurus nobilis L., 6-aminonicotinamide, boric acid, acetyl-L-carnitine, and coconut oil, may serve as antidotes by reducing the deleterious oxidative properties of ALP (Karimani et al., 2018). Intralipid emulsion (ILE) rescue therapy provides another potential strategy for the treatment of ALP toxicity, most likely by providing a lipid layer safety net for substance and drug overdose by passive diffusion. Clinicians are urged to embrace an expanded role of ILE rescue therapy, not only for local anesthetic drug toxicities but also for other lipophilic drug and substances overdoses (Muller et al., 2015).

In Egypt, despite the growing number of patients appearing in the emergency departments each year with this easily available poison in the market, very little effort has been put forth to study this topic scientifically and to prevent the ongoing loss of precious lives. The low survival rate following ALP poisoning and the magnitude of these poisoning-related deaths have drawn a great deal of attention in Egypt. This forementioned fact together with the few reports that exist about forensic toxicology analysis and epidemiologic studies in ALP-related deaths were the major drive to design the present study in Mansoura Emergency Hospital (MEH). The current study aims to evaluate the effect of ILE therapy as a putative antidote on the survival time of ALP intoxicated patients and whether it ameliorates the clinical outcome or not.

\section{Subjects and Methods:}

The clinical study was conducted at Mansoura Emergency Hospital (MEH), Mansoura University in Egypt involving the ALP intoxicated patients. A prospective study was conducted on patients presented with acute ALP toxicity in the period between January 2016 to January 2018 where they received the standard treatment protocol together with ILE. For patients who received only standard therapy, retrospective data were collected from patients' files for the ALP intoxicated patients admitted between January 2014 to December 2015. Patients above 12 years old, with a history of acute ingestion of ALP tablets and clinical manifestations confirming the ingestion, were included in the study. Cases excluded from the study were those less than 12 years old, incomplete clinical data, history of intervention before arrival to the hospital, history of ingestion of other toxins than ALP, pregnant females, any comorbidity as cardiac, hepatic, or renal diseases.

Sociodemographic variables including age and sex were documented, and clinical data including symptoms and clinical presentation, type of the treatment protocol, initial cardiac arrest rhythm, return of spontaneous circulation (ROSC), clinical outcome (died or discharged alive), and survival time were documented. Biochemical analysis of complete comprehensive metabolic panel, routine organ function investigation, complete blood count was measured on admission and regular basis during the whole length of hospital stay. Patients' data were registered in a special sheet and were completely anonymous and confidential. The 
study was approved by the Institutional Research Board (IRB) at the Faculty of Medicine, Mansoura University, Egypt.

\section{Treatment Protocol:}

1. ABCD stabilization

2. Gastric Gavage with coconut oil.

3. Infusion of $\mathrm{MgSO} 4$ started at $1 \mathrm{~g} / \mathrm{h}$ for the first $24 \mathrm{~h}$ then tapered to $1 \mathrm{~g}$ every 6 hourly. Serum magnesium was closely monitored (Baruah et al., 2015).

4. Standard ICU protocols include positioning of the patient, O2 therapy, fluid therapy, GIT prophylaxis, use of sedation when indicated, IV access, urinary catheterization, airway management, and mechanical ventilation (MV). Antibiotic therapy (if indicated) (Ghazi, 2013).

5. During ICU stay with monitoring of serum triglyceride, the patient received intralipid emulsion 20\% (Intralipid 20\%: A 20\% I.V Fat Emulsion Manufactured by Fresenlus Kabl. Uppsala, Sweden for Baxter Healthcare Corporation, Deerfield, IL 60015 USA) and this is where it gets challenging, following the protocols published by the American Society of Regional Anesthesia (ASRA) and the association of the Anesthetists of Great Britain and Ireland (AAGBI): 1, 2, $3 \mathrm{ml} / \mathrm{kg}$ of ILE $20 \%$ (approximately $100 \mathrm{ml}$ with average adult weight) as initial bolus dose starting 5-20 minutes after poisoning. Repeated boluses of the same dose were repeated 2-3 times every 5 minutes up to $300 \mathrm{ml}$ for persistent cardiovascular collapse. Continuous infusion rate of $0.25 \mathrm{ml} / \mathrm{kg} / \mathrm{min}(15 \mathrm{ml} / \mathrm{kg} / \mathrm{hr})$ followed and doubled to $0.5 \mathrm{ml} / \mathrm{kg} / \mathrm{min}$ permissible for continued hemodynamic instability when Blood pressure remain low. The infusion was continued for at least 10 minutes after circulatory stability. The recommended upper limit of $10 \mathrm{ml} / \mathrm{kg}$ over the first 30 minutes was followed. It is important to note that three initial doses were used: 100 $\mathrm{ml}, 200 \mathrm{ml}$, and $300 \mathrm{ml}$ (The Association of Anaesthetists of Great Britain \& Ireland, 2010; Gosselin et al., 2016, Macala et al., 2018).

\section{Statistical analysis:}

The statistical analysis was performed using the SPSS software for Windows, version 20.0. Categorical variables were presented as numbers and percentages and continuous data were presented as Mean \pm SD if parametric and as median, if nonparametric. Normality of data was tested using Kolmogorov-Smirnov test. Overall survivals were assessed using the Kaplan-Meier test with log-rank (Mantel-Cox) was used to determine the significance of mortality rate. The proportions of demographic characteristics and outcomes were compared using the Pearson chi-squared test for associations. For all used statistical tests, the threshold of significance is fixed at a 5\% level (p-value).

\section{Results:}

Eighty-seven ALP intoxicated cases were recruited from the Department of Clinical Toxicology, Mansoura Emergency Hospital (MEH), Mansoura University, Egypt. Data of 46 patients $(52.9 \%)$ were recruited from patient files for those who received the standard therapy (retrospective), while 41 patients $(47.1 \%)$ receive the standard therapy plus ILE (prospective). Of the 87 analyzed patients, $32(36.8 \%)$ were accidentally exposed to ALP, while 55 (63.2\%) individuals ingested ALP deliberately as an attempt to commit suicide. In most of the cases, ALP tablets were being used as a rodenticide in households or the neighborhood, however, the 
exact number of tablets ingested was not always outlined. Among the studied population, the youngest was 13 years old while the oldest was aged 47 years with Mean \pm SD $28.23 \pm 9.69$ years. The age and sex of studied patients are illustrated in table (1) and figures (1\&2).
The clinical presentation of the studied 87 cases is illustrated in the table (1). Initial cardiac arrest rhythm and return of spontaneous circulation (ROSC) for dead 59 cases are illustrated in the table (1).

Table (1): Clinical data among the overall intoxicated cases ( $\mathrm{n}=87$ patients).

\section{Parameters}

\section{Age}

\section{(minimum-maximum)}

$28.23 \pm 9.69$

(13 - 47) years

Parameters

Number (\%)

\section{Sex (87 patients)}

Male

Female

$31(35.6 \%)$

$56(64.4 \%)$

Mode of ingestion/exposure (87 patients)

Accidental

$32(36.8 \%)$

Deliberate

Symptoms and clinical presentations among patients reported as having aluminum phosphide poisoning (87 patients)

Nausea and vomiting

Metabolic acidosis

Hemodynamic disorders

Loss of consciousness

$55(63.2 \%)$

\section{Outcome}

Survived to discharge

$50(57.5 \%)$

$61(70.1 \%)$

$68(78.2 \%)$

Died

$56(64.4 \%)$

Initial cardiac arrest rhythm (59 patients)

Shockable

$28(32.2 \%)$

Non-Shockable

$27(31 \%)$

$32(36.8 \%)$
ROSC $^{\text {a }}$ (59 patients)
Yes
No

$35(40.2 \%)$

$24(27.6 \%)$

Mortality rate ${ }^{b}$

\begin{tabular}{lc}
\multicolumn{1}{c}{ Parameters } & Mean \pm SD \\
Survival Time ${ }^{\mathbf{c}}$ (hours) (59 patients) & \\
Intoxicated cases received only Standard therapy. & $27.93 \pm 18.41$ hours \\
Intoxicated cases received Standard therapy + ILE. & $49.781 \pm 14.63$ hours
\end{tabular}

SD: Standard Deviation. ${ }^{\mathrm{a}}$ ROSC: Return of spontaneous circulation. ${ }^{\mathrm{b}}$ Overall mortality rate among the whole studied population.

${ }^{\mathrm{c}}$ Survival time: the time starting from a defined point (hospital administration) to the occurrence of a given event (death). 


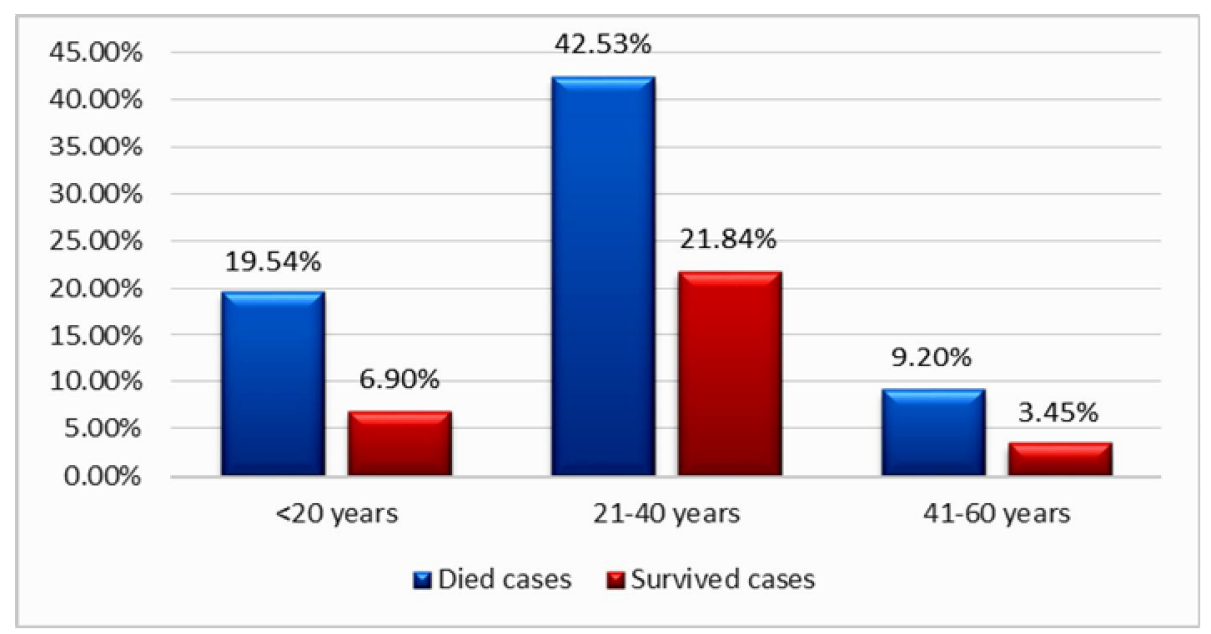

Fig. (1): The outcome of aluminum phosphide intoxicated cases (survived versus died) in association to age group.

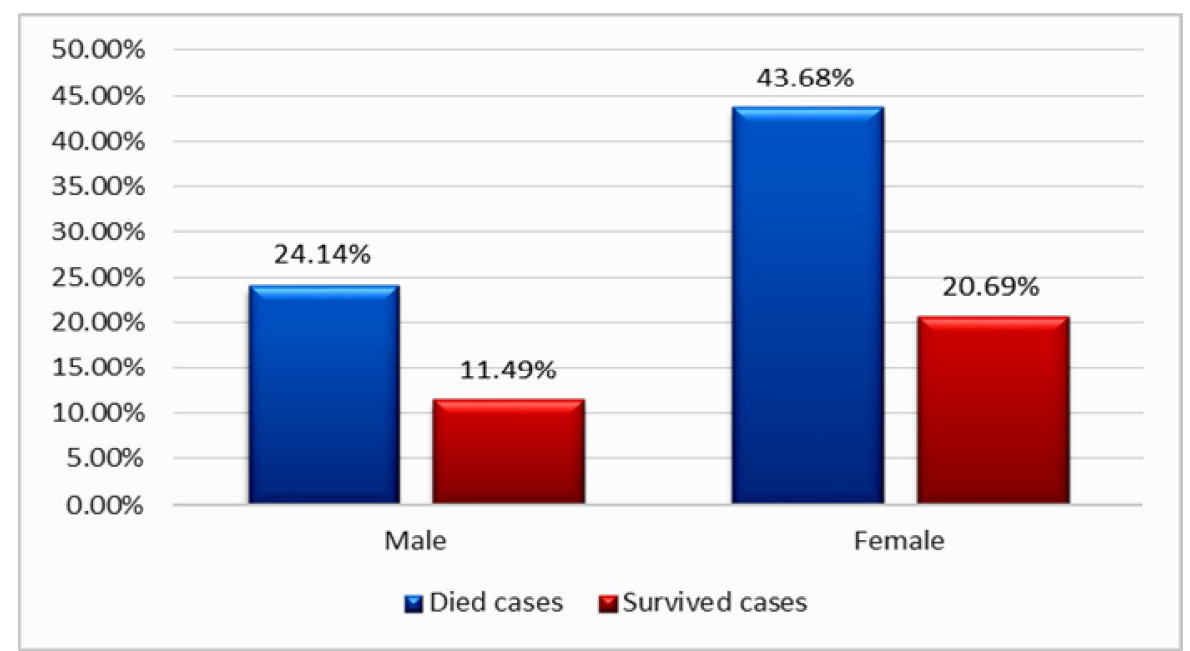

Fig. (2): The outcome of aluminum phosphide intoxicated cases (survived versus died) in association to sex.

Differences between age groups and sex about the outcome of ALP poisoning showed no statistically significant difference $p=0.657$ and $p=0.991$ respectively. All survived cases $(\mathrm{n}=28,32.2 \%)$ suffered no cardiac arrest, whilst of the 59 died cases, $54.2 \%$ suffered non-shockable rhythm with statistically significant difference $p=0.001$ compared to shockable rhythm demonstrated in 27 cases representing $45.8 \%$ of the dead individuals (Table 2).
The time interval between ingestion of poison and starting treatment therapy + ILE was $6.73 \pm 2.12$ hours. Of the 87 cases admitted, $59(67.8 \%)$ died. The mortality rate among the whole studied population was $67.8 \%$. Of the patients who died, the Mean \pm SD of the survival time following the standard therapy was $27.93 \pm 18.41$ hours, whilst that for individuals who received the standard therapy + ILE was $49.781 \pm 14.63$ hours (Table 1). Most deaths occurred between 2548 hours (Table 3 ). 
Table (2): The outcome of aluminum phosphide poisoning cases (survived vs died) in association to age group, sex, initial cardiac arrest rhythm and planned therapy.

\begin{tabular}{|c|c|c|c|}
\hline Parameters/variables & $\begin{array}{c}\text { Non-survivor } \\
\text { (n=59 patients) } \\
n(\%)\end{array}$ & $\begin{array}{c}\text { Survivor group } \\
\text { (n=28 patients) } \\
n(\%)\end{array}$ & $\begin{array}{l}\text { Test of significance } \& \boldsymbol{P} \text {-value } \\
\text { (Chi-square results) }\end{array}$ \\
\hline \multicolumn{4}{|l|}{ Age groups } \\
\hline$\leq 20$ years & $17(28.8 \%$ & $6(21.4 \%)$ & \multirow{3}{*}{$0.839, \mathrm{df}=2, P=0.657$} \\
\hline $21-40$ years & $34(57.6 \%)$ & $19(67.9 \%)$ & \\
\hline 41-60 years & $8(13.6 \%)$ & $3(10.7 \%)$ & \\
\hline \multicolumn{4}{|l|}{ Sex } \\
\hline Male & $21(35.6 \%)$ & $10(35.7 \%)$ & \multirow[t]{2}{*}{$0.000 \mathrm{df}=1, P=0.991$} \\
\hline Female & $38(64.4 \%)$ & $18(64.3 \%)$ & \\
\hline \multicolumn{4}{|l|}{ Initial cardiac arrest rhythm } \\
\hline No arrest & 0 & 28 & \multirow{3}{*}{$87.000 \mathrm{df}=2, P=<0.001 *$} \\
\hline Shockable & $27(45.8 \%)$ & 0 & \\
\hline Non-Shockable & $32(54.2 \%)$ & 0 & \\
\hline
\end{tabular}

$\mathrm{n}$ : number; $\mathrm{p}$ value is significant if $<0.05 . *$ : significant.

The association between the therapy of ALP poisoning cases (standard vs standard therapy + ILE) and age group, sex, initial cardiac arrest rhythm, clinical outcome, survival rate, and survival time is presented in table (3). A highly statistically significant difference was encountered when comparing both groups; standard therapy vs. standard therapy + ILE regarding the survival time $p=$ 0.001 , however, no statistically significant difference was shown about mortality rate. Figure (3) shows the Kaplan-Meier graph demonstrating the effect of standard therapy versus standard therapy +ILE administration on mortality of ALP intoxicated cases. ILE therapy could not prevent mortality. The median survival time following standard therapy was 24 hours, whilst that following standard therapy+ ILE is 48 hours with a highly statistically significant difference $p=$ 0.001 . For individual doses, the median survival times are the same among the three studied (48 hours) as shown in figure (4). 
Table (3): The protocol/therapy of aluminum phosphide (ALP) poisoning cases (standard vs standard therapy +ILE) in association to age group, sex, initial cardiac arrest rhythm, clinical outcome, survival rate, and survival time.

\begin{tabular}{|c|c|c|c|}
\hline & $\begin{array}{c}\text { Standard therapy } \\
\text { (Retrospective) } \\
\text { (n=46 patients) } \\
\text { n (\%) }\end{array}$ & $\begin{array}{c}\text { Standard therapy }+ \text { ILE } \\
\text { (Prospective) } \\
\text { (n=41 patients) } \\
\text { n (\%) }\end{array}$ & $\begin{array}{l}\text { Test of significance } \& \boldsymbol{P} \text {-value } \\
\text { (Chi-square results) }\end{array}$ \\
\hline \multicolumn{4}{|l|}{ Age groups } \\
\hline$\leq 20$ years & $16(34.8 \%)$ & $7(17.1 \%)$ & \multirow{3}{*}{$5.544, \mathrm{df}=2, P=0.063$} \\
\hline $21-40$ years & $27(58.7 \%)$ & $26(63.4 \%)$ & \\
\hline $41-60$ years & $3(6.5 \%)$ & $8(19.5 \%)$ & \\
\hline \multicolumn{4}{|l|}{ Sex } \\
\hline Male & $13(28.3 \%)$ & $18(43.9 \%)$ & \multirow[t]{2}{*}{$2.312, \mathrm{df}=1, P=0.128$} \\
\hline female & $33(71.7 \%)$ & $23(56.1 \%)$ & \\
\hline \multicolumn{4}{|l|}{$\begin{array}{l}\text { Initial cardiac } \\
\text { arrest rhythm }\end{array}$} \\
\hline No arrest & $19(41.3 \%)$ & $9(22 \%)$ & \multirow{3}{*}{$19.734, \mathrm{df}=2, P=<0.001 *$} \\
\hline Shockable & $20(43.5 \%)$ & $7(17.1 \%)$ & \\
\hline Non-Shockable & $7(15.2 \%)$ & $25(61 \%)$ & \\
\hline \multicolumn{4}{|l|}{ Outcomes } \\
\hline Died & $27(58.7 \%)$ & $32(78 \%)$ & \multirow[t]{2}{*}{$3.720, \mathrm{df}=1, P=0.054$} \\
\hline Survived & $19(41.3 \%)$ & $9(22 \%)$ & \\
\hline \multicolumn{4}{|l|}{ Survival time $^{\dagger}$} \\
\hline 6-24 hours & $14(30.4 \%)$ & $3(7.3 \%)$ & \multirow{3}{*}{ 15.472, $\mathrm{df}=2, P=<0.001 *$} \\
\hline $25-48$ hours & $10(21.7 \%)$ & $14(34.1 \%)$ & \\
\hline 49-72 hours & $3(6.5 \%)$ & $15(36.6)$ & \\
\hline
\end{tabular}

ILE: intrepid emulsion; $n$ : number. ${ }^{\dagger}$ Measured for the cases who died. P-value is significant if $<0.05 .{ }^{*}$ : significant.

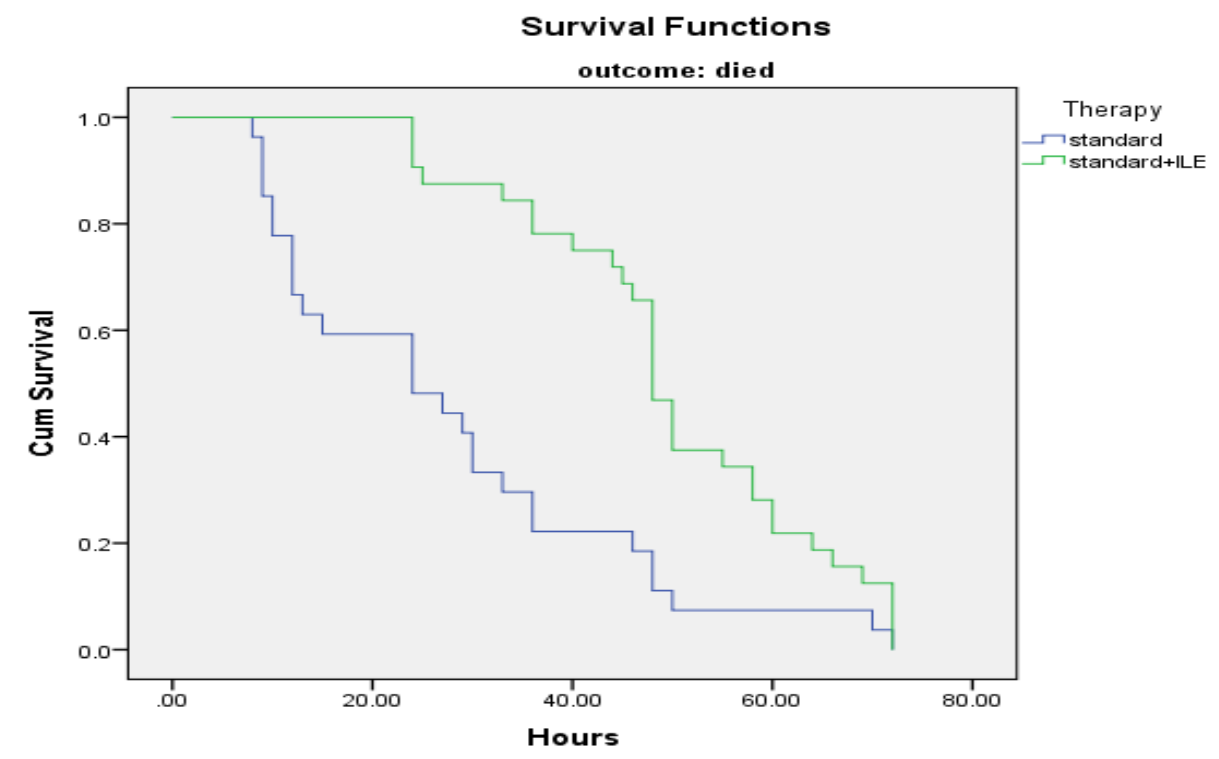

Fig. (3): Kaplan-Meier graph depicting survival rate and time following aluminum phosphide intoxication with subsequent treatment with either standard therapy alone or standard therapy \& intralipid emulsion (standard therapy + ILE). 


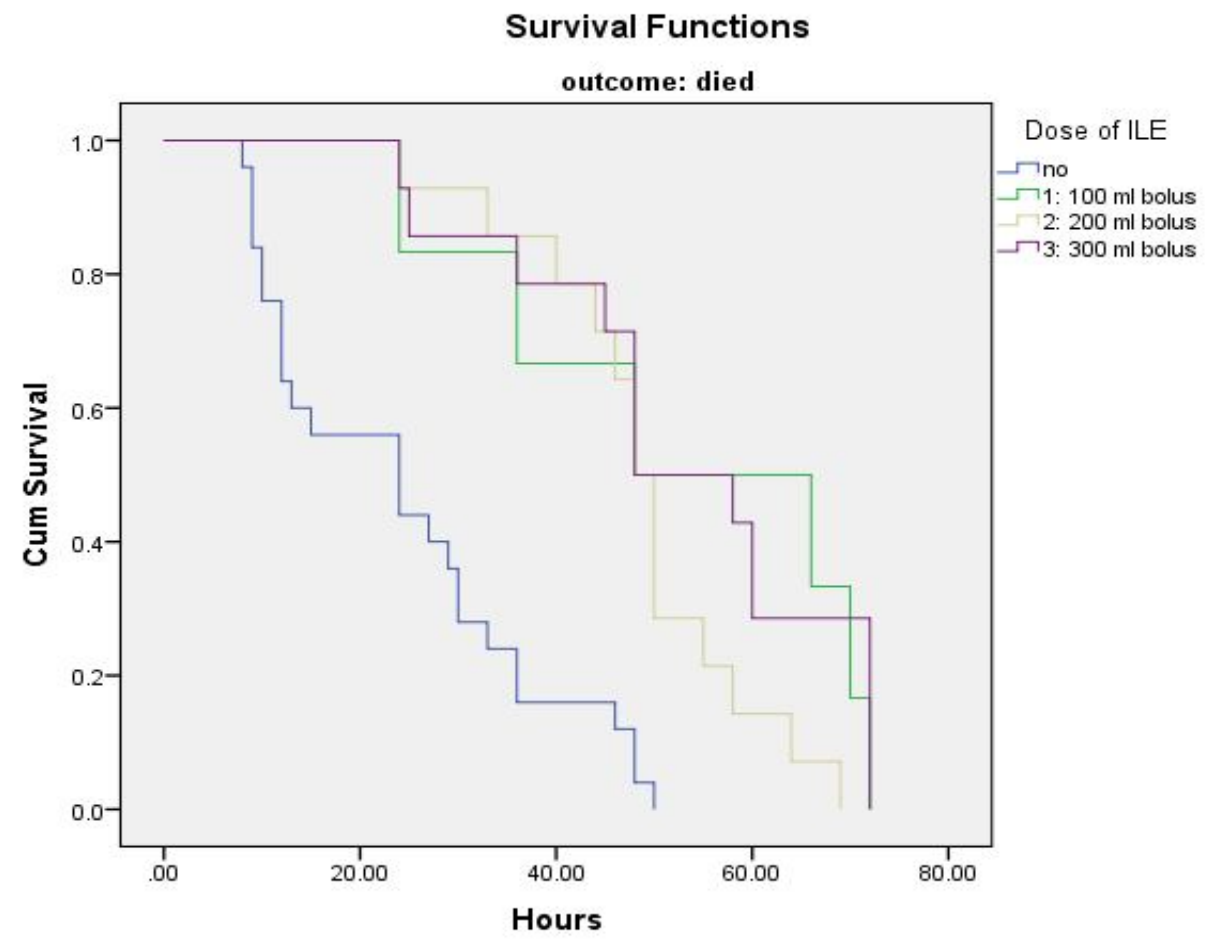

Fig. (4): Kaplan-Meier graph depicting survival rate and time following aluminum phosphide intoxication and subsequent treatment with either standard therapy alone (no) or (1): standard therapy \& intralipid emulsion at dose $1 \mathrm{ml} / \mathrm{kg}$ (100 $\mathrm{ml}$ bolus); (2) standard therapy \& intralipid emulsion at dose $2 \mathrm{ml} / \mathrm{kg}$ (200 ml bolus); (3) standard therapy \& intralipid emulsion at dose $3 \mathrm{ml} / \mathrm{kg}$ (300 $\mathrm{ml}$ bolus)

\section{Discussion:}

Aluminum phosphide is commonly known in Egypt as "Wheat pill" is a highly fatal poison with serious detrimental effects that reach up to death in severe poisoning conditions (Nosrati et al., 2013; Alnasser et al., 2018). Clinical presentation depends upon the amount of the ingested poison and the time passed since the onset of ingestion or exposure, There is no antidote to phosphine or metal phosphide poisoning and the reported mortality rate is very high even with adequate resuscitative and supportive measures offered in suitable time (Proudfoot, 2009). Intralipid is commonly used in the clinical setting for parenteral nutrition replacement and is now used as an antidote for lipid-soluble drugs (Vinnars and Wilmore, 2003). The question remains as to whether ILE provides effective properties as an antidote for the reversal of toxicity. In highlighting the use of ILE in the treatment of lipophilic drug toxicity e.g., local anesthetic drugs, the current study aimed to evaluate the effect of ILE therapy as a putative antidote on the survival time of ALP intoxicated patients and whether it ameliorates the clinical outcome or not.

Although the exact mechanism of intralipid reversal remains unknown, the lipid sink phenomenon has remained the most likely (Muller et al., 2015). Several studies 
have portrayed the lipid sink as the creation of an intravascular lipid layer that extracts the lipophilic molecules from target receptors thereby lessening its toxic effects and increasing its metabolism (French et al., 2011; Ozcan and Weinberg, 2014; Fettiplace et al., 2015).

Other proposed mechanisms of action of ILE include direct effects on the myocardium, relating to inotropic effects and improving cardiac cell survival (Stehr et al., 2007; Partownavid et al., 2012; Fettiplace et al., 2013; Fettiplace et al., 2015) and increased fatty acid uptake by mitochondria, thereby allowing the replenishing of ATP stores despite toxic inhibition of fatty acid transport systems (French et al., 2011; Weinberg and Riou, 2012; Ozcan and Weinberg, 2014; Muller et al., 2015).

As a lipid sink, the composition of the utilized ILE, in particular the type and concentration of fatty acids, is likely to have an important role (Siqueira et al., 2011). Intralipid $20 \%$ contains only one oil 'soybean oil' with mainly long-chain poly-unsaturated fatty acids. The composition of Intralipid $20 \%$ may provide better sequestration of lipidsoluble agents than other ILE consisting of a greater proportion of medium-chain fatty acids (Mazoit et al., 2009, Tang et al., 2016). Thus, health practitioners must avoid replacing intrepid $20 \%$ with other ILE without revising the resuscitative properties of these formulations (Macala et al., 2018).

Regarding the doses of ILE in utility, low-dose Intralipid 20\% (1 mL/kg) did not improve cardiac contractility or blood flow, either when administered alone or immediately after the onset of toxicity (Macala and Tabrizchi, 2014). These findings may lead to a common concept that at low doses, ILE act mainly to alter the pharmacokinetic profile of lipid-soluble toxins, whereas at high doses the direct cardiac effects occur. This is consistent with the observation that high doses of Intralipid (6-16 mL/kg) (Macala et al., 2018), despite the improvement of cardiac sodium channel blockade effect indicated by QRS prolongation), did not ameliorate overall survival in the wake of toxicity. Three low doses of ILE $20 \%$ were used in the present study: $1,2,3 \mathrm{ml} / \mathrm{kg}$ over $1 \mathrm{~min}$ as initial bolus dose immediately following poisoning identification. However, no significant difference has been encountered regarding the overall median survival time when comparing both studied groups received standard therapy versus standard therapy+ILE. The finding that the three used ILE doses did not have a significant difference is consistent with the previously reported results by Macala and Tabrizchi, 2014 indicating doses higher than 1 $\mathrm{mL} / \mathrm{kg}$ for Intralipid $20 \%$ do not add additional benefits in the treatment of lipophilic toxicity. The reason might be that if low doses of ILE could effectively lessen toxicity, higher doses might induce side effects that counterbalance the survival advantage. From a clinical point of view, lower administered doses, and volumes, are more likely to be tolerated by patient populations with impaired cardiovascular function (e.g., congestive heart failure) and may explain why higher doses did not award added protection.

These findings support the concept that I can be a life-saving therapy for patients experiencing cardiovascular collapse associated with lipophilic toxins (Cave and Harvey, 2009; Zein ELabdeen et al., 2020).

The overall mortality rate in our study was $67.8 \%$ : $58.7 \%$ among the patients who received the standard therapy and $78 \%$ for the group who followed standard therapy plus ILE. Similar studies in Morocco conducted between January 1992 and December 2002 and in Saudi Arabia between March 2006 to December 2017 reported a mortality rate 
between 32-62\% (Murali et al., 2009; Alzahrani et al., 2017; Alnasser et al., 2018). Another study in Iran showed overall mortality of $31 \%$, with $50 \%$ being male with a mean age of 27.1 years (Shadnia et al., 2009). One more Iranian study reported that $93 \%$ of cases were self-poisoning with suicidal intent (Mehrpour et al., 2012). In other studies, mortality reported was $47 \%$ and $58.6 \%$ (Srivastava et al., 2005; Soltaninejad et al., 2012; El Hangouche et al., 2017). In a clinical study was done in a tertiary care hospital in Lahore, there was a mortality rate of $70 \%$ (Ghazi, 2013) and another study also reports a mortality rate of $55-90 \%$ (Iftikhar et al., 2011). Conclusively, the mortality rate from ALP poisoning ranges from $37 \%$ to $100 \%$ (Bumbrah et al., 2012; Alnasser et al., 2018).

Cardiac toxicity among cases of ALP poisoning is due to phosphine (PH3) induced myocardial damage. Clinically, acute cardiovascular collapse, hemodynamic instability, and metabolic acidosis are the most common presentations seen in $60 \%$ to $100 \%$ of cases ( Tripathi et al., 1992; Elabbassi et al., 2014). Likewise, 68\% and $61 \%$ of the intoxicated patients included in the current study showed hemodynamic disorders and metabolic acidosis respectively. The most common cause of mortality within 12-24 hours of presentation is usually a cardiovascular cause such as hypotensive shock and/or arrhythmias. However, liver failure is the usual cause of death after 24 hours (Ghazi, 2013). Our findings demonstrated that administration of ILE has no significant effect on the survival rate and was not enough to prevent mortality however, to increase the survival time where the median survival time following standard therapy was 24 hours, whilst that following standard therapy+ILE is 48 hours with highly statistically significant difference $p=0.001$. For individual doses, the median survival times were the same among the three studied
(48 hours). Therefore, the volume of ILE showed no impact on the improvement of the clinical outcome.

In this context, an important issue for developing an antidote is knowing the maximum effective time lag between poisoning and antidote administration. This parameter was assessed. The time interval between ingestion of poison and starting treatment therapy + ILE was $6.73 \pm 2.12$ hours in the present study. The effect of this time lag on mortality may serve as a cause of yet higher mortality rate despite significant improvement of survival time. Although these results might pose themselves as limitations of the present study it gives a realistic view of toxicity among humans. Additional factors that increase the mortality rate in acute ALP toxicity cases are multiorgan failure that may complicate these cases. The effect of ILE on ALP-induced multiorgan failure awaits further investigations to pave the way to elucidate the protective mechanism of ILE in ALP intoxication.

\section{Conclusion and Recommendations:}

We reported that administration of ILE increases the time of survival in ALP intoxicated patients. However, it doesn't decrease the mortality rate. Further studies are essential to prove if ILE could be considered in the CPR measures of poisoning cases.

\section{Conflicts of interest statement:}

"The authors certify that they have NO affiliations with or involvement in any organization or entity with any financial interest or non-financial in the subject matter or materials discussed in this manuscript". 


\section{Acknowledgment}

The authors wish to thank the kind personnel of the Department of Clinical Toxicology, Mansoura Emergency Hospital $(\mathrm{MEH})$, Mansoura University, Egypt for their co-operation in this study.

\section{References:}

Alnasser, S., Hussain, S. M., Kirdi, T. S., et al. (2018). 'Aluminum phosphide poisoning in Saudi Arabia over nine years', Annals of Saudi Medicine, 38, p. 277-283.

Alzahrani, S. H., Ibrahim, N. K., Elnour, M. A., et al. (2017). 'Five-year epidemiological trends for chemical poisoning in Jeddah, Saudi Arabia', Annals of Saudi Medicine, 37, p. 282289.

Anand, R., Binukumar, B. K. and Gill, K. D. (2011). 'Aluminum phosphide poisoning: An unsolved riddle', Journal of Applied Toxicology, 31: p. 499-505.

Baruah, U., Sahni, A. and Sachdeva, H. C. (2015). 'Successful management of aluminum phosphide poisoning using intravenous lipid emulsion: Report of two cases', Indian Journal of Critical Care Medicine, 19, p. 735-738.

Bumbrah, G. S., Krishan, K., Kanchan, T., et al. (2012). 'Phosphide poisoning: A review of the literature', Forensic Science International, 214 (1-3), p. 16.

Cave, G. and Harvey, M. (2009). 'Intravenous lipid emulsion as antidote beyond local anesthetic toxicity: A systematic review', Academic Emergency Medicine, 16, p. 815-824.
El Hangouche, A. J., Fennich, H., Alaika, O., et al. (2017). 'Reversible myocardial injury and intraventricular thrombus associated with aluminium phosphide poisoning', Case Reports in Cardiology, 2017, p. 1-6.

Elabbassi, W., Chowdhury, M. A. and Fachtartz, A. A. N. (2014). 'Severe reversible myocardial injury associated with aluminum phosphide toxicity: A case report and review of the literature, Journal of the Saudi Heart Association, 26, p. 216-221.

Fettiplace, M. R., Ripper, R., Lis, K., et al. (2013). 'Rapid cardiotonic effects of lipid emulsion infusion', Critical Care Medicine, 41, p. 156-162.

Fettiplace, M. R., Lis, K., Ripper, R., et al. (2015). 'Multi-modal contributions to detoxification of acute pharmacotoxicity by a triglyceride microemulsion, Journal of Controlled Release, 198, p. 62-70.

French, D., Armenian, P., Ruan, W., et al. (2011). 'Serum verapamil concentrations before and after Intralipid therapy during treatment of an overdose', Clinical Toxicology, 49, p. 340-344.

Ghazi, M. A. (2013). 'Wheat Pill (Aluminum Phosphide) Poisoning '; Commonly ignored dilemma. A comprehensive clinical review'. Professional Med J, 20, p. 855-863.

Gosselin, S., Hoegberg, L. C. G., Hoffman, R. S., et al. (2016). 'Evidence-based recommendations on the use of intravenous lipid emulsion therapy in poisoning', Clinical Toxicology, 54, 899-923.

Hassanian-Moghaddam, H., Zamani, N., Rahimi, M., et al. (2016). 'Successful treatment of aluminium phosphide poisoning by extracorporeal membrane 
oxygenation', Basic and Clinical Pharmacology and Toxicology, 118, p. 243-246.

Iftikhar, R., Tariq, K., Saeed, F., et al. (2011). Wheat pill, clinical characteristics and outcome. PAFMJ, 61 (3). Retrieved from https://pafmj.org/index.php/PAFMJ/ar ticle/view/909

Karimani, A., Mohammadpour, A. H., Zirak, M. R., et al. (2018). 'Antidotes for aluminum phosphide poisoning An update', Toxicology Reports, 5, p. 1053-1059.

Macala, K. and Tabrizchi, R. (2014). 'The effect of fat emulsion on hemodynamics following treatment with propranolol and clonidine in anesthetized rats', Academic Emergency Medicine, 21, p. 12201225 .

Macala, K. F., Khadaroo, R. G., Panahi, S., et al. (2018). 'Low dose Intralipid resuscitation improves survival compared to ClinOleic in propranolol overdose in rats', PLOS ONE, 13, p. 113.

Mazoit, J. X., Le Guen, R., Beloeil, H., et al. (2009). 'Binding of long-lasting local anesthetics to lipid emulsions', Anesthesiology, 110, p. 380-386.

Mehrpour, O., Jafarzadeh, M. andAbdollahi, M. (2012). 'A systematic review of aluminum phosphide poisoning', Arhiv za Higijenu Rada I Toksikologiju, 63, p. 61-73.

Muller, S. H., Diaz, J. H. and Kaye, A. D. (2015). 'Clinical applications of intravenous lipid emulsion therapy, Journal of Anesthesia, 29, p. 920-926.

Murali, R., Bhalla, A., Singh, D., et al.
(2009). 'Acute pesticide poisoning: 15 Years experience of a large NorthWest Indian hospital', Clinical Toxicology, 47, p. 35-38.

Nosrati A., Karami M. and Esmaeilnia M. (2013). 'Aluminum phosphide poisoning: A case series in north Iran", Asia Pac J Med Toxicol, 2(3), p. 111113

Ozcan, M. S. and Weinberg, G. (2014). 'Intravenous lipid emulsion for the treatment of drug toxicity, Journal of Intensive Care Medicine, 29, p. 59-70.

Partownavid, P., Umar, S., Li, J., Rahman, S., et al. (2012). 'Fatty-acid oxidation and calcium homeostasis are involved in the rescue of bupivacaine-induced cardiotoxicity by lipid emulsion in rats', Critical Care Medicine, 40, p. 2431-2437.

Proudfoot, A. T. (2009). 'Aluminium and zinc phosphide poisoning', Clinical Toxicology, 47, p. 89-100.

Sankhla, M. S., Kushwah, R. S., Sharma, K., et al. (2017). 'Aluminium phosphide: a fatal poisoning', Interdiscip. Toxicol, 8, p. 65-67.

Shadnia, S., Sasanian, G., Allami, P., et al. (2009). 'A retrospective 7-years study of aluminum phosphide poisoning in Tehran: Opportunities for prevention', Human and Experimental Toxicology, 28, p. 209-213.

Singh, S. and Bhalla, A. (2015). 'Aluminum phosphide poisoning', Journal of Mahatma Gandhi Institute of Medical Sciences, 20, p. 1-5.

Siqueira, J., Smiley, D., Newton, C., et al. (2011). 'Substitution of standard soybean oil with olive oil-based lipid emulsion in parenteral nutrition: Comparison of vascular, metabolic, and inflammatory effects', Journal of Clinical Endocrinology and 
Metabolism, 96, p. 3207-3216.

Soltaninejad, K., Nelson, L. S., Bahreini, S. A., et al. (2012). 'Fatal aluminum phosphide poisoning in Tehran-Iran from 2007 to 20100', Indian Journal of Medical Sciences, 66, p. 66-70.

Srivastava, A., Peshin, S. S., Kaleekal, T., et al. (2005). "An epidemiological study of poisoning cases reported to the National Poisons Information Centre, All India Institute of Medical Sciences, New Delhi', Human and Experimental Toxicology, 24, p. 279285.

Stehr, S. N., Ziegeler, J. C., Pexa, A., et al. (2007). 'The effects of lipid infusion on myocardial function and bioenergetics in L-bupivacaine toxicity in the isolated rat heart', Anesthesia and Analgesia, 104, p. 186-192.

Tang, W., Wang, Q., Shi, K., et al. (2016). 'The Effect of Lipid Emulsion on Pharmacokinetics of Bupivacaine in Rats: Long-Chain Triglyceride Versus Long- and Medium-Chain Triglyceride', Anesthesia and Analgesia, 123, p. 1116-1122.

The Association of Anaesthetists of Great Britain \& Ireland 2010 (2010). AAGBI Safety Guideline Management of Severe Local Anaesthetic Toxicity. Available at:
https://anaesthetists.org/Portals/0/PDF s/Guidelines PDFs/ Guideline management_severe_local_anaesthetic toxicity_v2_2010_final.pdf?ver $=201$ $\overline{8}-07-11-163 \overline{7} 55-240 \&$ ver $=2018-07-$ 11-163755-240.

Tripathi, S.K., Gautam, C.S. and Sharma, P.L. (1992). Clinical pharmacology of aluminum phosphide poisoning, Indian J Pharmacol., 24, p. 134-137

Vinnars, E. and Wilmore, D. (2003). 'History of parenteral nutrition, Journal of Parenteral and Enteral Nutrition, 27, p. 225-232.

Weinberg, G. L., and Riou, B. (2012). 'Lipid emulsion infusion: resuscitation for local anesthetic and other drug overdose', Anesthesiology, 117, p. 180-187.

Zein ELabdeen, S. N., Saad, K.M., Oreby, M.M., and Elgazzar. F.M. (2020). 'Assessment of intravenous lipid emulsion as an adjuvant therapy in acute aluminum phosphide poisoning: A randomized controlled trial', Ain Shams Journal of Forensic Medicine and Clinical Toxicology, 34, p. 51-68. 


\section{تقييم دور مستحلب الدهون الوريدي كترياق واعد لعلاج التسمم الحاد بفوسفيد الألومنيوم}

\section{يـا سمين محمد تعلب'، منار عادل حلمي'، علياء أبـا الحسن عثمان'}

' قسم الطب الثرعي والسموم الإكلينيكية ـكلية الطب- جامعة المنصورة

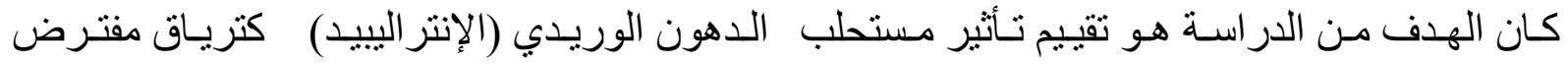
ومقيـاس إنعـاش نـاجح، على مدة بقـاء مرضـى التسمم الحـاد بفوسفيد الألومنيوم علي قيد الحيـاة ومـا إذا كـان

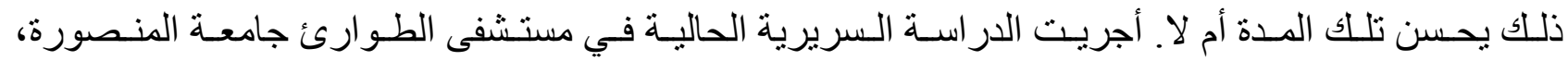

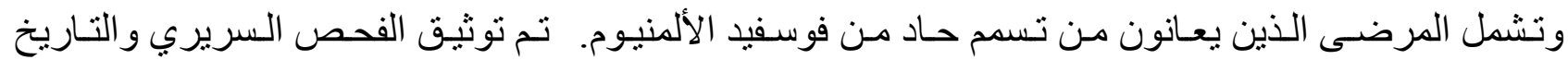
الاجتماعي و الديمو غر افي الكامل. تلقى المرضى إما العلاج القياسي أو العلاج القياسي بالإضـافة إلى مستحلب

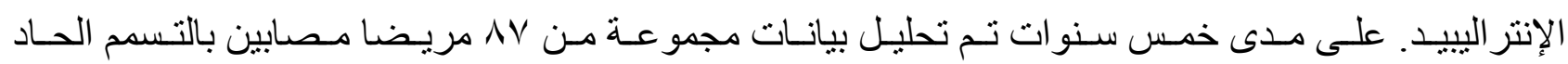

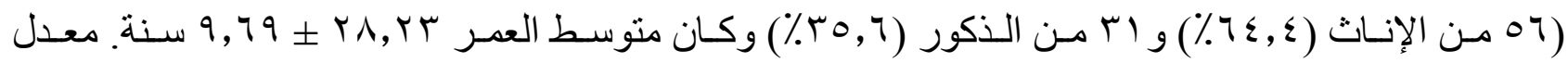

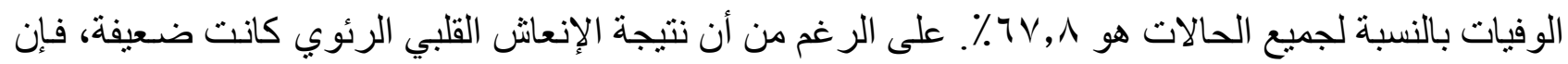

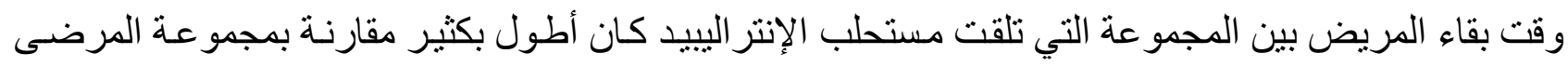

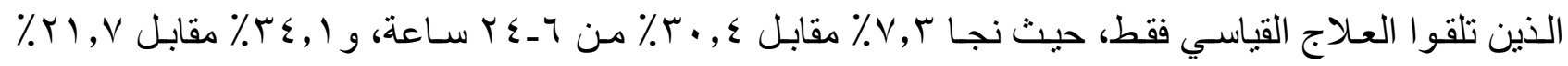

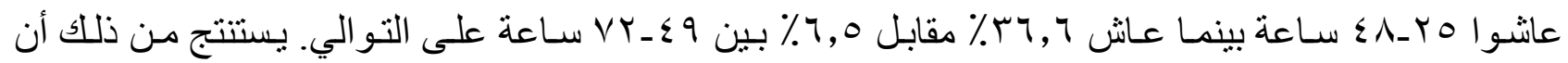
استخدام مستحلب الإنتر اليبيد كتريـاق أنتاء الإنعاش القلبي الرئوي بعد التسمم الحاد بفوسفيد الألومنيوم أظهر

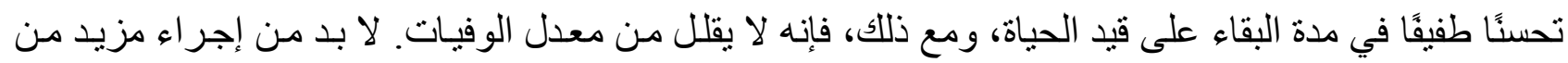
الدر اسات لإثبات فعاليته كترياق لسمية فوسفيد الألومنيوم وما إذا كان يمكن استخدامه في الإنعاش القلبي الرئوي لحالات التسمم. 